\title{
RETRATOS DA MOBILIDADE ESPACIAL NO BRASIL: OS CENSOS DEMOGRÁFICOS COMO FONTE DE DADOS
}

\author{
José Marcos Pinto da Cunha*
}

\begin{abstract}
Os Censos Brasileiros apresentam uma grande riqueza de informações que, por serem, de maneira geral, comparáveis ao longo tempo, representam uma grande oportunidade para se conhecer diferentes aspectos da dinâmica populacional brasileira. Tendo em vista a grande importância da migração na história demográfica nacional, este artigo pretende resgatar alguns aspectos teóricos e metodológicos para o uso dos dados censitários, de forma a orientar pessoas interessadas em aprofundar seus conhecimentos sobre o fenômeno.
\end{abstract}

Palavras-chave: Migração; Migração interna; Fontes de dados demográficos; Censos demográficos.

\section{Introdução}

Uma das principais características dos Censos Demográficos brasileiro é, sem dúvida nenhuma, sua riqueza em termos das informações sobre migração. De fato, é notório e reconhecido internacionalmente que nenhum outro Censo no mundo possui a variedade e a quantidade de questões sobre os movimentos migratórios oferecidas por nossos Censos, em particular a partir do de 1970.

É mesmo admirável que, juntamente com a grande evolução em termos de qualidade e processo de levantamento de informações, o IBGE tenha tido a sensibilidade de manter - a despeito até de recomendações internacionais um conjunto de questões que permitem ao pesquisador conhecer várias das

* Demógrafo, doutorado em Ciências Sociais pela Universidade Estadual de Campinas e pós-doutorado no "Population Research Center" da Universidade do Texas em Austin, professor associado do Departamento de Demografia do Instituto de Filosofia e Ciências Humanas e pesquisador do Núcleo de Estudos de População, ambos da Unicamp. E-mail: zemarcos@nepo.unicamp.br. Campinas/Brasil. 
facetas dos movimentos populacionais ocorridos no Brasil, nas últimas cinco décadas. Além de comparáveis, os dados até aqui levantados nos diversos Censos Demográficos representam uma grande oportunidade para se conhecer um dos aspectos mais complexos da dinâmica populacional brasileira.

Nossa história demográfica mostra que a migração, em suas diferentes modalidades, esteve presente em todas as fases do processo de desenvolvimento econômico/social e ocupação territorial no país. Desde a imigração estrangeira, incluindo o triste período do tráfico de escravos, principalmente no século XIX, passando pelo amplamente conhecido e discutido êxodo rural dos anos 1950, 1960 e 1970, até os dias de hoje, quando a mobilidade intermunicipal de mais curta distância ganha atenção por sua importância nas dinâmicas locais, a verdade é que os deslocamentos espaciais da população constituem um aspecto central para compreender o processo de redistribuição demográfica no território nacional, bem como as causas e consequências das desigualdades regionais e sociais que, infelizmente, até hoje caracterizam o Brasil.

Esse breve artigo, sem a pretensão de ser original e muito menos exaustivo, busca resgatar alguns aspectos metodológicos sobre o uso dos dados censitários, de maneira a orientar o leitor interessado em aprofundar seus conhecimentos sobre o fenômeno e os dados existentes.

\section{Um pouco de polêmica: migração ou mobilidade espacial da população? ${ }^{1}$}

Pode até ser por preciosismo acadêmico, mas parece que a questão sobre a definição de migração não é consensual entre os estudiosos. Assim, poderia ser levantada a seguinte pergunta: faz alguma diferença chamar determinado fenômeno que envolva "deslocamentos de indivíduos no espaço" de migração ou, mais genericamente, de mobilidade espacial? Do nosso ponto de vista, a resposta seria afirmativa.

Como lembram Wunsch e Termote $^{2}$ mobilidade espacial referese à "habilidade" de se mover no espaço, fenômeno que pode envolver tanto a migração, considerada a mudança de lugar de residência, como os movimentos diários, entre os quais os mais conhecidos são os pendulares. De fato pode-se dizer que,

sob um conceito amplo e mal definido, mesclam-se processos complexos e diversificados, que emergem na resultante

Esta seção baseia-se na introdução do livro CUNHA, Jorge Marcos (org.). Mobilidade Espacial da População: desafios teóricos e metodológicos para o seu estudo.

2 WUNSCH, Guillaume; TERMOTE, Marc. Introduction to Demographic Analysis, p. 196. 
redistribuição da população no espaço. Desde mudanças de residência relacionadas a momentos do ciclo vital até movimentos que significam etapas de ascensão na escala social, diversos e complexos são os fatores subjacentes aos deslocamentos populacionais de uma área a outra. ${ }^{3}$

Ou seja, partir de reflexões que considerem não apenas uma terminologia mais ampla, mas também uma visão mais complexa do que seria a movimentação da população no espaço, poderia representar, a priori, uma vantagem para melhor se compreender a real característica, os condicionantes e as consequências da dinâmica da população nos seus vários contextos socioespaciais. De fato, a experiência acadêmica nessa área de estudos - seja no Brasil,seja em outras partes do mundo - mostra que a diversidade e complexidade de movimentos contemporâneos exigem não somente novos esforços teóricos e metodológicos, mas também a ampliação das fontes e dos tipos de dados coletados.

A respeito desta questão, estamos em muito boa companhia quando nos reportamos ao clássico texto de Zelinsky ${ }^{4}$ sobre a "transição da mobilidade"5 em que o autor, tentando compreender o motivo de os estudos migratórios terem sido tão negligenciados em favor daqueles relativos à fecundidade e outros tópicos da demográfica, considera que: "The essential reasons are to be found in the intrinsic nature of the phenomenon, in definitional problems, and in the difficulties of data procurement and analysis. But exactly who is a migrant, and what do we mean by migration?"6.

Zelinsky ${ }^{7}$ apresenta a noção de "mobilidade territorial", considerando que o termo "is comprehensive, combine conventional (that is, residential) migration with what, for lack of a better designation, can be called 'circulation'". Segundo o autor:

The conventional definition of migration may serve after a fashion for the totality of territorial mobility in the initial and

PATARRA, Neide; CUNHA, João Marcos P. "Migração um tema complexo", p. 32.

4 ZELINSKY, Wilbur. "The hypothesis of the mobility transition".

5 Esse estudo, na sua época, inovou ao pensar os diferentes momentos da mobilidade territorial a partir de um corte espaço-temporal, tratando de estabelecer uma relação entre a distintas formas de mobilidade e os momentos do desenvolvimento econômico e tecnológico da sociedade. Apesar de instigantes, em particular para a época em que foram divulgadas, as proposições apresentadas são baseadas em paradigmas ligados ao enfoque neoclássico enraizado na teoria de modernização, apoiado nas ideias de um modelo difusionista, com influência do determinismo tecnológico e a-histórico, no sentido que pressupõe que as etapas concebidas a partir de experiência europeia seriam necessariamente vivenciadas por todas as sociedades. Para mais detalhes sobre a crítica a esse enfoque, ver DE HASS, Hein. Migration and development: a theoretical perspective.

6 ZELINSKY, op. cit., p. 223.

7 Ibidem, p. 225. 
intermediate stages of the mobility transition. But the volume, intensity, and nature of circulation in advanced communities is such that there is no realistic alternative to treating all territorial mobility as a single continuum...8

No entanto, isso não significa descartar a noção de migração. Afinal, esta variável é parte constitutiva do pensar demográfico, já que representa um dos três pilares a partir dos quais é possível estudar a modificação do tamanho, a estrutura e a distribuição espacial da população. Não implica, portanto, abandonar ideias já consolidadas, ou propor uma nova maneira de se pensar a dinâmica demográfica. Na verdade, pode-se dizer que rotular determinado movimento como migração, ou algum outro tipo de mobilidade espacial, dependeria muito menos de conceitos herméticos predefinidos do que da real definição do fenômeno como objeto de estudo.

De nossa parte, preferimos pensar a migração a partir de duas perspectivas: por um lado, como fenômeno demográfico; e, por outro, enquanto processo social. Mesmo tendo em conta que tal separação tende a ser artificial, uma vez que pelo menos os demógrafos, de maneira geral, não estabelecem a separação destas duas dimensões, não há como negar que, entendida como componente do crescimento demográfico, a migração não apresenta qualquer problema quanto à sua definição: será considerado desta forma qualquer movimento que modifique o tamanho e a estrutura da população.

De fato, embora as várias definições encontradas em textos especializados ou em manuais tenham um caráter normativo quanto ao que deve ou não ser considerado migração, é preciso levar em conta que tal postura estaria muito mais atrelada à necessidade de padronização ou à disponibilidade de dado do que propriamente a uma definição, ou, o que seria muito mais complexo, a uma conceitualização do que seria o fenômeno. "For a movement to be considered a migration, it must be across a political or administrative boundary, and involve a change of 'usual residence'"'9.

Como se nota na definição acima, o caráter normativo (caracterizado pelo termo "must") fica muito claro, uma vez que considera migração apenas o movimento que se dá entre divisões políticas administrativas. Outra definição mais "flexível", embora bem mais indefinida, é proposta pelas Nações Unidas em seu famoso manual sobre migração: "traslado de una zona definitoria de la migración a otra (o un traslado a una distancia mínima especificada) que se ha hecho durante un intervalo de migración determinado y que ha implicado un cambio de residencia"10.

8 Ibidem, p. 226.

9 BILSBORROW, Richard. Migration, urbanization, and development, p. 3 (grifo nosso).

${ }^{10} \mathrm{NACIONES}$ UNIDAS. Métodos de medición da la migración interna, p. 2. 
Neste caso fica bem mais aberta a possibilidade de se pensar em deslocamentos entre unidades espaciais diversas e não necessariamente constituídas formal ou administrativamente. Zelinsky também oferece uma definição utilizando um adjetivo muito sugestivo: "genuína". "Genuine migration obviously means a perceptible and simultaneous shift in both spatial and social locus"11. É interessante notar que Zelinsky coloca uma nova dimensão (além da espacial e temporal) para a caracterização da migração, ou seja, o espaço social do indivíduo. Para o autor, migrar não seria apenas mudar de lugar, mas também romper vínculos sociais. Certamente essa questão traz novas alternativas para a presente discussão, mas isso foge do escopo do presente artigo.

De qualquer forma, uma característica tem balizado todas estas definições e impõe novamente uma grande dificuldade para estabelecer a noção de migração, em particular na atualidade: a mudança de residência. De fato, como mostram Domenach e Picouet ${ }^{12}$ é cada vez mais difícil definir o que seria uma mudança permanente ou não de domicílio, o que colocaria em xeque, portanto, qualquer definição como as anteriormente mencionadas. Essa questão também poderia ser constatada no texto de Bilsborrow: "In fact, the use of the term permanent should be avoided, as neither the migration is permanent...nor is the residence; indeed, the lack of permanence is inherent in the definition of migration itself"13.

Contudo, voltando nossa atenção à migração como fenômeno demográfico, é possível dizer que todas estas questões, se não perdem importância, ao menos seriam relativizadas. Enquanto componente do crescimento populacional, qualquer entrada ou saída de pessoas, independentemente da escala espacial, no período de tempo considerado, deveria ser considerada migração; ou seja, do ponto de vista puramente demográfico, o que interessa é saber como a população de determinado território - seja um país, um Estado, um município ou até mesmo um pequeno bairro - foi modificada ao longo de um período de tempo pela movimentação de pessoas que poderiam incrementar (os imigrantes) ou reduzir (os emigrantes) o seu tamanho (e composição).

Já do ponto de vista do fenômeno como processo social, certamente a compreensão e o conceito do que seria migração deveriam sofrer forte interferência em função da forma como os concebemos - a construção do objeto -, sobretudo como aspectos constituintes de dinâmica socioespacial.

11 ZELINSKY, op. cit., p. 224.

12 DOMENACH, Hervé; PICOUET, Michel. "El carácter de la reversibilidad en el estudio de la migración".

13 BILSBORROW, op. cit., p. 5. 
De certa maneira, a definição de migração dependeria muito mais do enfoque e interesses do pesquisador do que propriamente dedados, divisões administrativas ou convenções preexistentes. Talvez um exemplo interessante deste tipo de questão que se impõe ao pesquisador seria o conceito de "espaço de vida" desenvolvido por Courgeau ${ }^{14}$. Entendida como "porção do espaço no qual o indivíduo realiza todas suas atividades", esta forma de relacionar o indivíduo com o território poderia, por exemplo, levar uma definição do tipo: "las migraciones son entendidas como un traslado que suponen un cambio del espacio de vida de los individuos"15.

Ou seja, uma proposição claramente independente de um recorte político-administrativo que tende a nortear as definições, por assim dizer, orientadas pelo enfoque demográfico. Obviamente, as dificuldades conceituais e, sobretudo, operacionais para a realização de estudos tendo como ponto de vista o "espaço de vida" tornam esta opção um desafio muito maior. Assim, o que poderíamos compreender como migração a partir de um ponto de vista poderia não sê-lo a partir de outro.

Um caso exemplar desta discussão seria a migração (ou mobilidade residencial) intrametropolitana, fenômeno que não apenas interfere no crescimento e na forma das grandes aglomerações urbanas do país, mas também reflete, em muitos sentidos, a redistribuição da população no espaço metropolitano. ${ }^{16}$ Assim, embora implique em mudança de residência (não importa se em caráter definitivo ou não), este tipo de movimento não necessariamente resulta em mudanças de espaço de vida e, portanto, nos termos definidos acima não constituiria migração. Aliás, um dos tipos de deslocamento espacial mais "populares" (e no nosso entender nada demográfico) entre os estudiosos hoje em dia, a "mobilidade pendular", seria uma das faces mais visíveis deste processo: muda-se de lugar, mas não se perde o vínculo preexistente com o território.

Seja qual for nossa inclinação ou, melhor dizendo, nossa necessidade em termos analíticos de visualizar a migração, a verdade é que, contrariamente ao que acontece com as outras duas variáveis demográficas - mortalidade e fecundidade -, sua definição abre enormes flancos para discussão. É bem verdade que espaço e tempo são centrais em sua definição, mas várias questões se colocam: que espaço (ou escala espacial) seria relevante para

\footnotetext{
${ }^{14}$ COURGEAU, Daniel. Méthodes de Mesure de la Mobilité Spaciale: migration internes, mobilité temporaire, navettes.

${ }^{15}$ GIUSTI, Alejandro; CALVELO, Laura. "En busca de una medición de la reversibilidad", p. 29.

${ }^{16}$ CUNHA, João Marcos P. et alii. "Expansão metropolitana, mobilidade espacial e segregação nos anos 90: o caso da RM de Campinas"; IDEM. "La Movilidad Intrarregional en el Contexto de los Cambios Migratorios en Brasil en El Período 1970-1991: El Caso de La Región Metropolitana de São Paulo".
} 
ser considerado? Que tempo ou período seria o ideal para uma adequada análise da migração? Seria realmente possível falar sobre um caráter definitivo da mudança domiciliar? No cenário contemporâneo das migrações, substituir a ideia de definitivo por residência usual, como tem sido feito, seria suficiente para resolver os problemas de captação de dados sobre migração?

Estamos de acordo com Bilsborrow quando ele afirma que "...as the field of migration advances, albeit slowly, it has become clear that there are kinds of migration besides the usual so-called 'permanent' or 'long-term' migration involving an unambiguous change of usual residence"17.

O que se percebe, portanto, é que, se no passado, particularmente nos países em desenvolvimento como o Brasil, quando a migração de mais longa distância era a que ditava o compasso do fenômeno, talvez fosse mais fácil pensar a migração a partir de categorias mais herméticas como origem/ destino, urbano/rural, industrial/não industrial, etc., hoje a questão se coloca de forma mais complexa.

Em outras palavras, se no passado a complexidade e a diversidade das formas de mobilidade espacial da população eram ofuscadas pelas grandes tendências históricas da migração no Brasil, em particular a migração rural-urbana, e até mesmo pela falta de dados, hoje elas se manifestam com toda força, não apenas reproduzindo alguns aspectos já observáveis nas décadas anteriores, mas também apresentando novas feições, fenômenos, condicionantes e consequências.

Dessa forma, pensar de maneira mais geral na mobilidade espacial da população talvez fosse o mais adequado tanto para nos desprendermos de certos pressupostos e visões ultrapassadas que nos acompanharam até pouco tempo, quanto para vislumbrarmos novos conceitos, novas relações entre estes movimentos populacionais e, mais do que isso, novas formas de compreender a dinâmica demográfica de nosso país e mais especificamente de nossas cidades e aglomerações urbanas.

Neste sentido, vale a pena um breve, mas não menos importante, alerta teórico suscitado pelo destacado sociólogo José de Souza Martins ${ }^{18}$. Para ele, tão importante quanto definir quem é ou não migrante é considerar outra categoria: a dos não migrantes. Segundo Martins, sendo a migração uma consequência esperada para se garantir a busca de meios de sobrevivência na sociedade moderna, o interesse maior deveria ser com o "não migrante". Preocupado com a forma como o indivíduo se insere socialmente, o autor

17 BILSBORROW, op. cit., p. 5.

${ }^{18}$ MARTINS, José de Souza. A sociedade vista do abismo: novos estudos sobre exclusão, pobreza e classes sociais. 
considera que o "sujeito que nunca saiu do lugar dele para ir para outro lugar para se reajustar nesse ciclo de exclusão/inclusão, não é normal"19. Ou seja, a partir desta perspectiva, não podemos esquecer que o "problema migratório" também faz parte a "imobilidade". A produção brasileira sobre migração possibilita afirmar que esta é, sem dúvida, uma dimensão que vem sendo sistematicamente negligenciada.

Migração ou mobilidade espacial da população? Seja lá qual for o termo mais adequado (não se pretende aqui estabelecer qualquer tipo de consenso), o mais importante a ser considerado por aqueles que se preocupam ou se interessam por este tema é o fato que esse fenômeno, complexo em função de suas múltiplas facetas, requer não apenas constantes e mais intensos esforços teóricos, mas também muito cuidado e habilidade no uso dos dados normalmente disponíveis, particularmente aqueles derivados dos Censos Demográficos e das PNADs.

Assim, mesmo em situações, diga-se de passagem, cada vez mais raras, em que existe a possibilidade de levantar seus próprios dados, o pesquisador da mobilidade espacial da população irá se deparar com várias dificuldades para captar ou definir adequadamente seu objeto de estudo. Desde aspectos relativos à equalização de recursos e quantidade/qualidade das informações desejadas, passando pela memória dos entrevistados, até as dificuldades intrínsecas das pesquisas transversais ${ }^{20}$, fazem com que o estudo desse fenômeno exija certa habilidade e, mais do que tudo, criatividade.

Nesse sentido, a próxima seção busca apresentar um breve panorama das possibilidades oferecidas pelos Censos Demográficos brasileiros que, como dito, são não apenas os mais ricos do mundo para o estudo da mobilidade espacial da população, mas também os mais confiáveis e com maior grau de desagregação espacial existente no país.

\section{Antes de começar: sobre as potencialidades e limitações das informações censitárias}

Quando se trata de utilizar uma fonte de dados, pode-se dizer que a melhor maneira de começar seria identificar minuciosamente suas qualidades, para medir ou diagnosticar o fenômeno de interesse e também estar atento às suas características e limitações.

\footnotetext{
${ }^{19}$ Ibidem, p. 126.

${ }^{20}$ Usamos esse termo em contraposição às pesquisas longitudinais que acompanham pessoas ou grupos de pessoas ao longo do tempo. Nesse caso, como é característica dos Censos Demográficos, a maior parte dos dados refere-se a um momento específico, no caso, a data de referência da pesquisa.
} 
Assim, a primeira providência a se tomar é conhecer profundamente o questionário. De fato, não se pode utilizar adequadamente uma base de dados sem saber como foram levantadas as informações, quem foram os entrevistados, etc. Pode parecer óbvio, mas a experiência mostra que parte significativa dos erros cometidos nas tabulações realizadas com base nos Censos e PNADs ocorre, em boa medida, em função do desconhecimento ou negligência de questões básicas associadas ao processo de levantamento de dados. Por exemplo, detalhes sobre quem responde ou não a determinado quesito, que tipo de código é atribuído para quem deixa de respondê-lo, qual o fluxo seguido na articulação das perguntas, etc. são elementos centrais para a boa utilização de uma fonte de dados.

Como instrumento de coleta, o questionário é, portanto, a base para o uso "responsável" dos dados, em especial os censitários. É claro que a qualidade dos dados não depende apenas do questionário, já que existem vários outros elementos intervenientes, como planejamento, amostra, treinamento dos entrevistadores, etc. Contudo, não há dúvida que sua qualidade em termos de conteúdo, diagramação e fluxo é basilar para a aquisição de um bom dado.

Da mesma forma, é impossível trabalhar adequadamente uma fonte de dados sem conhecer profunda e criteriosamente sua documentação, em particular o chamado livro de códigos (ou layout), instrumento que permite conhecer o nome e a codificação utilizada para cada variável de interesse. Felizmente, tanto no caso do Censo Demográfico quanto da PNAD esses documentos são, em geral, muito bem elaborados pelo IBGE.

Estas etapas prévias seriam, portanto, essenciais para aproveitar toda a riqueza do Censo Demográfico para criar as bases empíricas de qualquer análise proposta. No entanto, embora seja possível afirmar que a qualidade dos Censos Demográficos brasileiros é, em geral, muito boa e reconhecida internacionalmente, não se pode deixar de considerar que essa fonte tem um conjunto de limitações - a maior parte delas intrínsecas ao processo de levantamento de informações - que, via de regra, implicam dificuldades para o pesquisador, como as apresentadas a seguir:

1) Trata-se de uma "fotografia" de um momento específico (a data censitária): isso significa que a maior parte das informações coletadas, especialmente as relativas às características socioeconômicas, refere-se ao momento do censo.

2) A maioria das perguntas não tem caráter retrospectivo: tal limitação soma-se à anterior como problema para os estudos migratórios, uma vez que as características obtidas, em especial as dos migrantes, não coincidem com 
aquelas do momento da migração. Isso, via de regra, gera problemas para análise dos processos migratórios, pois pouco de sabe sobre a situação do migrante antes da data de referência do recenseamento;

3) Os dados dizem respeito apenas aos "sobreviventes" do processo migratório: no Censo Demográfico são captados somente os migrantes que permaneceram no lugar do recenseamento e que não faleceram no período intercensitário. Com isso, perde-se muito da riqueza do processo migratório ocorrido no período prévio ao Censo. Como mostra Martine ${ }^{21}$ em seu clássico estudo sobre a disjuntiva teórica entre a "adaptação" ou "sobrevivência dos mais fortes"22, essa limitação intrínseca dos Censos Demográficos pode gerar dificuldades para análise sobre o impacto e as consequências da migração nos locais e origem e destino;

4) Periodicidade e delimitação espacial restrita: apesar da riqueza do Censo brasileiro, sobretudo quando comparado aos de outros países, estas duas questões podem gerar frustrações para os analistas pelo fato de os dados rapidamente se distanciarem do período em que estes estão sendo analisados e por não recuperarem etapas migratórias em níveis espaciais mais desagregados, como é o caso, por exemplo, da escala intramunicipal e, agora em 2010, do rural/urbano.

Obviamente, a experiência da produção sobre migração no Brasil, especialmente a partir dos anos 1980, mostra que tais considerações nunca representaram obstáculos para o avanço do conhecimento do fenômeno e muito menos barreiras insuperáveis para estudos teórica e metodologicamente consistentes. No entanto, trata-se de elementos centrais que devem ser levados em conta quando se pretendem bom uso e interpretação dessas informações.

\section{A evolução dos dados censitários no Brasil ${ }^{23}$}

Em trabalho anterior abordando tema semelhante ao aqui desenvolvido ${ }^{24}$ salientava-se a importância de conhecer o processo de urbanização brasileiro, sobretudo tendo em vista as grandes transformações (e fases) pelas quais este passou ao longo do século XX e que foi acompanhado por significativas

\footnotetext{
${ }^{21}$ MARTINE, George. "Adaptação dos migrantes ou sobrevivência dos mais fortes?".

${ }^{22} \mathrm{Em}$ poucos palavras, trata-se das duas possibilidades para explicar porque os migrantes mais antigos sãotão diferentes dos mais recentes e assumem características, em particular socioeconômicas, mais próximasdaquelas dos nativos.

${ }^{23}$ Essa seção é uma versão atualiza de parte das considerações feitas em outro artigo intitulado Migração e urbanização no Brasil: alguns desafios metodológicos para análise", publicado em 2005 na Revista São Paulo em Perspectiva. Para maiores detalhes ver, CUNHA, João Marcos P. "Migração e Urbanização no Brasil: alguns desafios metodológicos para a análise".

${ }^{24}$ Ibidem.
} 
mudanças nas características dos fenômenos migratório, em particular em algumas de suas expressões. Assim, asseverava-se que "Tal é o caso da migração de retorno, que se intensificou significativamente a partir dos anos 80; dos movimentos intra-regionais que afloraram nesse período, revelando novas lógicas e 'espaços de migração'"25; dos fluxos migratórios intraestaduais, que refletem as relações existentes entre as áreas metropolitanas (ou grandes aglomerações urbanas) e o interior; e, finalmente, dos intrametropolitanos, que se reproduzem com formas semelhantes em praticamente todas as áreas metropolitanas do país, muito embora não necessariamente com os mesmos condicionantes. A essas modalidades não se poderia deixar de agregar os movimentos migratórios internacionais, que, a partir dos anos 1990, assumiram importância numérica, obrigando os demógrafos a reconsiderarem a hipótese de "Brasil como uma população fechada".

A mensuração e interpretação de todas essas formas de migração, sejam estas as mais tradicionais, recrudescentes ou emergentes, representam uma condição necessária - embora não suficiente - para se avançar na compreensão de parte considerável da dinâmica demográfica e da heterogeneidade socioespacial existente no país. De fato, deve-se considerar que, "além das grandes tendências em termos dos fluxos migratórios interestaduais, não se pode negligenciar a importância das dinâmicas intraregionais e especialmente intra-estaduais para se compreender o processo de redistribuição da população no Brasil"26.

Como já mencionado, é consenso entre os estudiosos do tema que os Censos Demográficos brasileiros, principalmente os quatros últimos (1980, 1991, 2000 e 2010), apresentam grandes potencialidades em termos da análise do fenômeno migratório. Além da representatividade e alcance espacial característicos destes levantamentos, tais Censos dispõem de grande número de itens especificamente voltados para apreender diferentes facetas do fenômeno, destacando-se aqueles que permitem estabelecer fluxos migratórios a partir da identificação do município de residência prévia.

Além disso, deve-se considerar que as potencialidades dos Censos Demográficos para o estudo da migração não se limitam aos quesitos levantados especificamente para a captação dos movimentos territoriais dos indivíduos. De fato, as oportunidades oferecidas por essa fonte crescem ainda mais se levarmos em conta a possibilidade dos inúmeros cruzamentos desses quesitos - que, como será visto, permitem criar diferentes modalidades ${ }^{27}$ de

\footnotetext{
${ }^{25}$ BAENINGER, Rosana. Região, Metrópole e Interior: espaços ganhadores e espaços perdedores nas migrações recentes - Brasil, 1980-1996.

${ }^{26}$ CUNHA, João Marcos; BAENINGER, Rosana, apud CUNHA, “Migração e Urbanização..., op. cit., p. 5.

${ }_{27}$ Note-se que utilizamos o termo "modalidade" para caracterizar indiscriminadamente o movimento
} 
migração - com as demais informações levantadas pelos Censos quanto às características demográficas e socioeconômicas da população.

Como mostram os trabalhos de Carvalho ${ }^{28}$, Martine ${ }^{29}$, Carvalho e Rigotti $^{30}$, Carvalho e Machado ${ }^{31}$ e Rigotti ${ }^{32}$, a correta utilização dos dados censitários sobre migração permite enfrentar uma série de questões relativas ao fenômeno. Tendo em vista a clareza e amplitude desses estudos mencionados, considera-se desnecessário reproduzir em detalhes aqui as várias possibilidades oferecidas pelos Censos Demográficos. Assim, o que se apresenta a seguir é apenas uma visão panorâmica da questão.

De maneira geral, pode-se dizer que, a partir dos dados censitários, seria possível identificar três modalidades de migração: 1) A interestadual; 2) A inter-municipal; 3) A migração entre situações de domicílio (rural-urbano, urbano-urbano etc.).

Nos dois primeiros casos, os quesitos sobre "lugar de nascimento", "residência anterior" (conhecida como "última etapa") e "residência cinco anos antes do Censo" (conhecida com "data fixa") seriam as possibilidades oferecidas, muito embora conceitualmente essas três informações sejam distintas. É bom lembrar também que para o "lugar de nascimento" não é possível estabelecer fluxos em nível municipal, já que essa informação não é levantada. ${ }^{33}$

Deve-se notar, no entanto, que estas três formas de captação sobre a residência prévia do indivíduo são distintas:

a) Lugar de nascimento: capta apenas os migrantes acumulados (life time migrants) sem, portanto, estabelecer um período de migração;

referido a determinada escala espacial. Assim, por exemplo,a modalidade "migração interestadual" diria respeito aos fluxos estabelecidos entre as distintas UF, da mesma forma que "migração intermunicipal" referir-se-ia àquela que envolve os municípios. Preferimos reservar o termo "tipo" para as modalidades que marcam ou predominam em momentos históricos distintos, como foi a migração internacional no final do século XIX e começo do XX, ou a migração rural-urbana, etc. Nesse sentido, "modalidade" e " tipo" seriam para nós noções distintas, embora intimamente relacionadas.

${ }^{28}$ CARVALHO, José Alberto M. "Estimativas indiretas e dados sobre migrações: uma avaliação conceitual e metodológica das informações censitárias recentes".

${ }^{29}$ MARTINE, George. "Os dados censitários sobre migrações internas: evolução e utilizações".

${ }^{30}$ CARVALHO, José Alberto M.; RIGOTTI, José Irineu. "Os dados censitários brasileiros sobre migrações internas: algumas sugestões para análise".

${ }^{31}$ CARVALHO, José Alberto M.; MACHADO, Cláudio C. "Quesitos sobre migrações no Censo Demográfico de 1991".

32 RIGOTTI, José Irineu R. Técnicas de mensuração das migrações, a partir de dados censitários: aplicação aos casos de Minas Gerais e São Paulo; e, mais recentemente, RIGOTTI, José Irineu R. "Dados censitários e técnicas de análise das migrações no Brasil: avanços e lacunas".

${ }^{33}$ Nem por isso o migrante intermunicipal deixa de ser captado, já que isso é possível com a pergunta "nasceu nesse município?". No entanto, nada se sabe sobre o município de nascimento, o que impossibilita a identificação de fluxos. 
b) Última etapa: refere-se apenas ao último movimento do indivíduo dentro do período intercensitário.

c) Data fixa: combina espaço (município e UF) e tempo (cinco anos atrás) e permite determinar a residência em uma data fixa no passado, especificando, ao contrário do quesito anterior, um período exato e local inequívoco para a migração.

Os Censos de 1980, 2000 e 2010 também levantam informação do que se convencionou a chamar de "movimento pendular", a partir da pergunta sobre lugar de trabalho e estudo. Contudo, em função das suas características - movimento diário sem caráter permanente - , tal fenômeno não deveria ser catalogado como migração, mas sim, genericamente, como um tipo de mobilidade populacional. ${ }^{34}$

Mesmo limitado a recortes espaciais que nem sempre satisfazem as necessidades dos pesquisadores - por exemplo, via Censo é impossível se pensar em mobilidade interbairros - , variações das modalidades de migrantes poderiam ser obtidas ao se combinarem as perguntas anteriores entre elas e com outras, como aquela referida ao "tempo de residência", o que amplifica ainda mais as possibilidades da informação censitária.

Nesse sentido, destaca-se que a definição mais detalhada da trajetória dos indivíduos permitiria a construção de tipologias mais complexas dos movimentos, o que, sem dúvida, contribuiria para o enriquecimento da compreensão dos processos migratórios, seus condicionantes e consequências.

Como mencionado, várias sugestões sobre cruzamentos possíveis a partir dos quesitos censitários sobre migração foram feitas por outros autores, em particular para o Censo de 1991, no qual, por primeira e única vez, o IBGE manteve duas informações sobre migração em nível municipal - a última etapa e data fixa. Mesmo que essa grande oportunidade tenha sido eliminada no Censo 2000, que captou apenas a informação sobre data fixa, a boa notícia é que o Censo de 2010 voltou a incorporar ambas as informações e, portanto, todo esse esforço poderá ser replicado para esses dados.

Em sua tese de doutoramento, Rigotti ${ }^{35}$ oferece uma excelente visão das várias possibilidades existentes em termos de cruzamentos. Em outro trabalho, o autor destaca que, "além de potencializar os estudos das etapas

\footnotetext{
${ }^{34}$ Essa visão se justifica na medida em que a mobilidade pendular não exerce efeito sobre o crescimento e estrutura demográficas de determinada região. No entanto, é possível que não haja consenso sobre isso, já que se poderia argumentar que tal tipo de mobilidade criaria uma "população flutuante" com impacto efetivo sobre a população local, mesmo que em momentos específicos do dia ou do período em que o fenômeno ocorre.

${ }^{35}$ RIGOTTI, Técnicas de mensuração..., op. cit.
} 
migratórias, a coexistência dos quesitos de última etapa e data fixa permite reconstituir a população no início do período quinquenal e fazer inferências sobre a emigração internacional"36.

O que é importante nas contribuições mencionadas são as alternativas oferecidas para o cruzamento de quesitos censitários visando criar novas modalidades de migração. Este é o caso específico da identificação de outros pontos nas trajetórias municipais, a partir do uso conjunto dos dados sobre "data fixa" e "última etapa", ou a identificação dos migrantes de retorno com o uso combinado de local de residência e local de nascimento. Vale lembrar que a migração de retorno foi uma das mais importantes facetas do processo migratório brasileiros nos anos $1990 .{ }^{37}$

Considera-se que a inclusão do Estado de nascimento nas possibilidades de combinações dos quesitos censitários pode implicar significativos aportes analíticos, sobretudo, se considerarmos a possibilidade de que, em alguns estudos concretos, a simples identificação de um ou dois pontos na história migratória individual pode escamotear parte importante do processo.

Esse tipo de ganho é típico, por exemplo, no caso dos estudos dos processos de metropolização de crescimento e expansão urbana das grandes cidades, no qual, em virtude do peso da mobilidade intrarregional, é mascarado, muitas vezes, o real processo migratório responsável pelo fenômeno que, via de regra, iniciou-se em outras regiões ou Estados. ${ }^{38}$ O mesmo ocorre com a migração para áreas de fronteira, como mostram Cunha $^{39}$ e Salim $^{40}$. Segundo este último autor, para o Centro-Oeste, podese observar "uma migração concentrada regionalmente, mas caracterizada pela razoável mobilidade interestadual, antes de situar-se na Região". Nesse caso, é bastante clara a necessidade de se conhecer mais detalhadamente a trajetória dos migrantes, para que se possa chegar a uma adequada interpretação das causas dessa migração.

Um detalhe metodológico importante sobre a migração interestadual é que a informação sobre residência anterior que consta nos Censos de 1980, 1991 e 2010 é, de certa forma, de natureza distinta daquela contida no Censo

${ }^{36}$ IDEM, “Dados censitários..., op. cit., p. 149.

${ }^{37}$ CUNHA, João Marcos P.; BAENINGER, Rosana. "Cenários da migração no Brasil nos anos 90".

${ }^{38}$ MATOS, Ralfo. A desconcentração populacional em Minas Gerais e as mudanças na RegiãoCore; CUNHA, João Marcos P. Mobilidade populacional e expansão urbana: o caso da Região Metropolitana de São Paulo.

${ }^{39}$ CUNHA, João Marcos P. Dinâmica migratória e o processo de ocupação do Centro-Oeste Brasileiro: o caso de Mato Grosso.

${ }^{40}$ SALIM, Celso A. Estrutura agrária e dinâmica migratória na Região Centro-Oeste, 1970-1980: análise do êxodo rural e da mobilidade da força de trabalho no contexto de industrialização da agricultura e da fronteira urbanizada. 
de 2000. Isso porque, nos três primeiros casos, a "UF anterior" declarada pelos migrantes está atrelada ao município anterior declarado e não seria, portanto, necessariamente a residência prévia real em termos dessa unidade espacial. Em 2000 este problema foi sanado na medida em que a pergunta foi feita diretamente sobre a UF e não sobre o município de residência anterior.

Específica dos Censos de 1991, 2000 e 2010, a informação sobre "município de residência em uma data fixa no passado" (no caso, 1986, 1995, 2005, respectivamente), não apenas permite que se reconstitua a população no meio do período intercensitário e, portanto, se obtenham estimativas de saldos migratórios para dois intervalos distintos de tempo ${ }^{41}$, mas também elimina um problema de referência espacial intrínseco à informação sobre o "município de residência anterior".

De fato, o município anterior pode não coincidir com a microrregião anterior ou o Estado anterior se houve um mudança intrarregional prévia, fato que prejudicaria o estudo adequado de fluxos populacionais em níveis espaciais mais agregados do que os municípios. Contudo, a informação sobre a residência em uma "data fixa" determina sem ambiguidade o local onde o indivíduo residia seja qual for o recorte espacial utilizado (há cinco anos a pessoa vivia no mesmo bairro que pertence a um único município que pertence a uma única região, etc.).

No entanto, esse tipo de informação possui também algumas limitações, das quais duas merecem destaque:

- por sua própria formulação, não é possível identificar a migração de menores de cinco anos, tendo essa lacuna que ser preenchida por métodos indiretos;

- não contempla os movimentos ocorridos no período entre o levantamento e a data fixada no passado. Esse é um dos motivos pelos quais tal informação é qualitativa e quantitativamente distinta daquela derivada da residência anterior para pessoas com menos de cinco anos de residência.

Ressalte-se que, embora seja possível afirmar que, desde 1960, todos os Censos brasileiros seriam comparáveis para os estudos migratórios, existem alguns problemas que interferem nessa comparabilidade. Vejamos alguns exemplos:

1. Migração segundo situação de domicílio: essa informação, não captada no Censo de 2010, foi mantida em 2000 de forma diferente da que vinha sendo levantada em Censos anteriores. Por isso, o uso combinado dos vários Censos a partir dessa informação deve ser feito com muito cuidado,

${ }^{41}$ CARVALHO, MACHADO, op. cit. 
pois conceitualmente a última etapa migratória (como vinha sendo feito até 1991) e a residência em uma "data fixa" como utilizada em 2000 são distintas. Infelizmente esse tipo de informação foi excluído do Censo de 2010, o que interrompe a série histórica e impossibilita continuar estudando esse tipo de fluxo que, no nosso entender, a despeito do elevado grau de urbanização alcançado pelo país, certamente ajudaria a compreender vários processos ainda em curso;

2. Migração intermunicipal: o Censo de 2000 é o único que não apresenta informação sobre a "última etapa migratória" a esse nível, o que dificulta, pelas mesmas razões acima, a comparabilidade entre os Censos, em particular os de 1980, 1991 e 2010. Por exemplo, para estudar o fenômeno ao longo dos anos 1970 até os 2000, é necessário fazer algum tipo de adaptação, já que, em 1980, não há informação sobre "data fixa". Uma forma de aproximação que vem sendo aceita pelos estudiosos do assunto é o uso da "última etapa" combinada com o tempo de residência inferior a cinco anos, contudo, sabe-se que, mesmo assim, teremos resultados formalmente não comparáveis. ${ }^{42}$ Problema semelhante terá o pesquisador que prefere utilizar a "última etapa migratória" ${ }^{\prime 3}$ como referência para estabelecer os fluxos migratórios, já que, em 2000, essa informação foi excluída. Deve-se lembrar, entretanto, que essa comparabilidade permanece, ao menos, em termos de Unidades da Federação, uma vez que, em 2000, a informação sobre última etapa foi mantida em nível estadual;

3. Mobilidade pendular: essa informação foi incluída pela primeira vez no Censo de 1970, repetida em 1980 e logo retirada em 1991. Felizmente foi novamente incluída em 2000 e 2010, sendo que, nesse último caso, foram incorporadas várias novidades, como a separação entre motivo de estudo e trabalho e até mesmo alguns detalhes sobre o deslocamento para o trabalho.

${ }^{42}$ Ou seja, tenta-se com isso delimitar, também para o Censo de 1980, um período temporal semelhante ao da "data fixa" coletado em 1991 e 2000, muito embora se saiba que, por não se tratar de um período exato de tempo, tal comparação fique teoricamente comprometida. Na verdade, ainda que delimitado por um corte temporal, não é possível saber a que período se refere o conjunto demigrantes de "ultima etapa", uma vez que estes são enumerados segundo distintos momentos de chegada (dado pelo tempo de residência).

43 Aqui vale uma explicação. A grande diferença entre a informação sobre "data fixa" e "última etapa" é que a primeira estabelece um período exato para se mensurar a migração, o que, do ponto de vista de algumas questões formais para estimativas demográficas, é muito desejável. No entanto, com isso perde-se, por exemplo, não apenas a migração de menores de cinco anos de idade estes ainda não haviam nascido cinco anos antes -, mas também toda a mobilidade existente nesse interstício. Para questões, por exemplo, que envolvem processos intrarregionais essa limitação pode implicar problemas ao captar volumes expressivos de fluxos nessa escala espacial. Além disso, considera-se que a "última etapa" permite captar com maior propriedade a realidade dos movimentos mais recentes, que, como mostram os dados censitários, representam parte expressiva da migração da década. 
Antes de concluir essa seção, vale uma breve menção a uma das grandes novidades trazidas pelo Censo Demográfico de 2010: dados inéditos sobre a migração internacional. Além dos tradicionais dados obtidos a partir dos quesitos sobre "última etapa", "data-fixa" e "tempo de residência", que até agora permitiam captar os imigrantes internacionais (ou pelo menos aqueles oficialmente "visíveis" ${ }^{44}$ ), o Censo 2010 coletou, em seu questionário do universo, a informação sobre parentes residentes fora do país. A partir da pergunta "alguma pessoa que morava com você(s) estava morando em outro país em 31 de julho de 2010?", o IBGE oferece à comunidade científica uma possibilidade única de avançar no conhecimento sobre e emigração para o exterior no Brasil.

Contudo, é importante reconhecer que, como afirma Martínez Pizarro $^{45}$, essa informação possui limitações, não sendo possível a partir dela obter uma estimativa confiável da emigração internacional.

Hoy sabemos que no se trata de una estimación de la emigración y que no cabe interpretar este resultado como magnitud de emigrados. Siempre habrá un sesgo desconocido en el que quedará excluida una parte de los hogares en los que todos sus miembros emigraron y una serie de circunstancias que impiden contabilizar el total de emigrados... ${ }^{46}$

Por outro lado, o mesmo autor elenca uma série de vantagens da informação para o estudo do fenômeno:

a) "se pueden conocer los lugares desde donde se emigra con distintos niveles de desagregación y también caracterizar a los hogares desde los que se parte, en contraste con aquellos que no registran miembros en el exterior;

b) se pueden analizar las tendencias recientes de la emigración, las características de los emigrantes al momento de salir del país de origen e identificar a los países de destino o residencia actual"47.

Ou seja, embora com limitações, pode-se dizer que o Censo Demográfico 2010 abre novas e interessantes janelas para o conhecimento de outra importante faceta do processo migratório nacional.

O Quadro 1 traz um resumo das informações disponíveis nos Censos Demográficos desde 1960.

\footnotetext{
${ }^{44}$ Estudos aqui e no exterior mostram que a captação do imigrante via Censo sempre fica prejudicada, sobretudo no caso dos migrantes ilegais (ou talvez melhor dito, indocumentados), que, por medo ou outro tipo de sentimento, acabam não sendo declarados.

${ }^{45}$ MARTÍNEZ PIZARRO, Jorge. La medición e información sobre la medición internacional a partir de los censos: lecciones, desafíos y oportunidades.

46 Ibidem, p. 8.

47 Ibidem, p. 8-9.
} 


\section{QUADRO 1 \\ Quesitos censitários relativos à mobilidade espacial da população - Brasil, 1960/2010}

\begin{tabular}{|c|c|c|c|c|c|c|}
\hline TIPO DE INFORMAÇÃO & 1960 & 1970 & 1980 & 1991 & 2000 & 2010 \\
\hline \multicolumn{7}{|l|}{ REFERÊNCIAS ESPACIAIS } \\
\hline UF de nascimento & $x$ & $x$ & $x$ & $x$ & $x$ & $x$ \\
\hline Nacionalidade & $x$ & $x$ & $x$ & $x$ & $x$ & $x$ \\
\hline Condição de naturalidade & $x$ & $x$ & $x$ & $x$ & $x$ & $x$ \\
\hline UF de residência anterior (última etapa) & $x$ & $x$ & $x$ & $x$ & $x$ & $x$ \\
\hline Município de residência anterior (última etapa) & & & $x$ & $x$ & & $x$ \\
\hline Situação do domicílio de residência anterior & $x$ & $x$ & $x$ & $x$ & $X(1)$ & \\
\hline Mobilidade intra-municipal entre situação & & & $x$ & $x$ & & \\
\hline UF de residência cinco anos antes (Data Fixa) & & & & $x$ & $x$ & $x$ \\
\hline Município de residência cinco anos antes (Data Fixa) & & & & $x$ & $x$ & $x$ \\
\hline Município de trabalho ou estudo & & $x$ & $x$ & & $x$ & $X(2)$ \\
\hline Morador do domicílio no exterior & & & & & & $X(3)$ \\
\hline \multicolumn{7}{|l|}{ REFERÊNCIAS TEMPORAIS } \\
\hline Tempo de residência no município & $x$ & $x$ & $x$ & $x$ & $x$ & $x$ \\
\hline Tempo de residência no Estado & & $x$ & $x$ & $x$ & $x$ & $x$ \\
\hline Tempo de residência no País & & & & $x$ & $x$ & $x$ \\
\hline Ano da última partida do moradores no exterior & & & & & & $X(3)$ \\
\hline
\end{tabular}

Fonte: IBGE. Censos Demográficos de 1960 a 2010.

(1) Nesse caso refere-se à data fixa.

(2) O Censo 2010 separa trabalho e estudo.

(3) Essa informação encontra-se no boletim do universo.

Em suma, pode-se dizer sem medo de errar que todo aquele que planeja ou já realize pesquisa na área de mobilidade espacial da população tem no Censo Demográfico uma excelente base de dados, cujas potencialidades vão além das imaginadas a partir do primeiro contato com os dados. Não custa lembrar que as Pesquisa Nacionais por Amostra de Domicílios (PNAD) também são fontes importantes para os estudos de migração, sendo que boa parte dos comentários realizados anteriormente pode ser aplicada a elas, uma vez que apresentam como principal diferencial o fato de terem uma amostra bem menor e, por isso, fornecerem informações sobre migração em nível espacial bem menos desagregado. Para mais detalhes sobre o uso das PNADs para os estudos migratórios, ver Cunha e Jakob ${ }^{48}$.

${ }^{48}$ CUNHA, João Marcos P.; JAKOB, Alberto Augusto. "O uso das PNAD’s na análise do fenômeno migratório: possibilidades e desafios metodológicos". 
A demografia e vários demógrafos brasileiros já mostraram que com os Censos e as PNADs é possível conhecer nossa realidade migratória com bom nível de detalhe e precisão metodológica. No entanto, é fundamental que todo aquele que se aventure no uso desses dados tenha presente que isso será possível somente com um bom nível de conhecimento dessas fontes, suas potencialidades e, principalmente, suas limitações.

\section{Considerações finais}

O presente artigo teve como principal motivação apresentar as potencialidades existentes nos Censos Demográficos brasileiros para o estudo da mobilidade espacial da população.

Precedidas por uma breve discussão de aspectos teórico/metodológicos que consideramos importantes para serem considerados em qualquer estudo sobre o tema, como as dificuldades conceituais para delimitar o fenômeno, ou mesmo as limitações inerentes à forma de elaboração de um Censo, as questões aqui tratadas visaram apresentar um guia geral das possibilidades analíticas que se abrem para os estudiosos da área.

Sem a intenção de ser exaustivo e muito menos de apresentar minuciosa e didaticamente as formas de utilização e/ou combinação dos quesitos censitários - até porque tal tarefa já foi desenvolvida por outros autores -, esse ensaio concentrou-se em mostrar as características dos quesitos censitários e como eles podem abrir oportunidades para se conhecer melhor a realidade dos deslocamentos territoriais no país. Acreditamos ter deixado claro que, mesmo não sendo uma tarefa de grande complexidade, a observação de certas especificidades das informações utilizadas é elemento central para uma captação correta e adequada do fenômeno.

Sendo a migração, ou mais genericamente, a mobilidade espacial da população um fenômeno multifacetado e, principalmente, multiescalar, sua definição nem sempre é imediata e óbvia. Mostramos que o Censo permite várias possibilidades de delimitação do tempo e espaço e que, portanto, as modalidades de movimentos por ele captadas podem ser variadas conforme se use um ou outro quesito censitário. Dessa forma, somente um bom entendimento do significado de cada um deles permitirá a melhor escolha.

Estudar a mobilidade espacial da população não é tarefa fácil, contudo, diante da sua importância na dinâmica demográfica e social de um país como o Brasil, é fundamental que mais e mais esforços sejam voltados para melhor conhecer empírica e teoricamente esse fenômeno. Esperamos que esse texto ajude nessa tarefa. Mãos à obra. 


\section{Bibliografia}

BAENINGER, Rosana. "Migrações internas no Brasil século 21: evidências empíricas e desafios conceituais", in CUNHA, João Marcos Pinto (org.). Mobilidade espacial da população: desafios teóricos e metodológicos para o seu estudo. Campinas: NEPO/UNICAM, 2011.

- Região, Metrópole e Interior: espaços ganhadores e espaços perdedores nas migrações recentes - Brasil, 1980-1996. Campinas, 1999. Tese (Doutorado) - Instituto de Filosofia e Ciências Humanas, Universidade Estadual de Campinas.

BILSBORROW, Richard. Migration, urbanization, and development: new directions and issues. New York: FNUAP, 1997.

CARVALHO, José Alberto Magno; RIGOTTI, José Irineu. "Os dados censitários brasileiros sobre migrações internas: algumas sugestões para análise", in Revista Brasileira de Estudos de População, v. 15, n. 2, 1998.

- "Estimativas indiretas e dados sobre migrações: uma avaliação conceitual e metodológica das informações censitárias recentes", in Revista Brasileira de Estudos de População, São Paulo, v. 2, n. 1, 1985.

; MACHADO, Cláudio Caetano. "Quesitos sobre migrações no Censo Demográfico de 1991", in Revista Brasileira de Estudos Populacionais, v. 9, n. 1, 1992.

COURGEAU, Daniel. Méthodes de Mesure de la Mobilité Spaciale: migration internes, mobilité temporaire, navettes. Paris: L'Institut National D'Estudes Démographiques, 1988.

CUNHA, João Marcos P.into. Dinâmica migratória e o processo de ocupação do Centro-Oeste Brasileiro: o caso de Mato Grosso. Campinas, 2004. Relatório de Pesquisa, mimeo.

- "La Movilidad Intrarregional en el Contexto de los Cambios Migratorios en Brasil en El Período 1970-1991: El Caso de La Región Metropolitana de São Paulo", in Notas de Población. Santiago de Chile: CELADE, 2000, p.149-185.

. "Migração e Urbanização no Brasil: alguns desafios metodológicos para a análise", in Revista São Paulo em Perspectiva, v. 19 n. 4, out./dez. 2005, p. 3-20.

. Mobilidade populacional e expansão urbana: o caso da Região Metropolitana de São Paulo. Campinas, 1994. 283f. Tese (Doutorado) - Instituto de Filosofia e Ciências Humanas, Universidade Estadual de Campinas.

; BAENINGER, Rosana. "Cenários da migração no Brasil nos anos 90", in Caderno do CRH, Salvador, v. 18 n. 43, 2005.

et alii. "Expansão metropolitana, mobilidade espacial e segregação nos anos 90: o caso da RM de Campinas", in IDEM (org.). Novas Metrópoles Paulistas: população, vulnerabilidade e segregação. Campinas: NEPO/UNICAMP, 2006. 
; JAKOB, Alberto Augusto E. "O uso das PNAD’s na análise do fenômeno migratório: possibilidades e desafios metodológicos", in CUNHA, João Marcos (org.). Mobilidade espacial da população: desafios teóricos e metodológicos para o seu estudo. Campinas: NEPO/UNICAM, 2011.

DE HASS, Hein. Migration and development: a theoretical perspective. UK: International Migration Institute, University of Oxford, Working papers, n. 9, 2008.

DOMENACH, Hervé; PICOUET, Michel. "El carácter de la reversibilidad en el estudio de la migración", in Notas de Población. Santiago de Chile: CELADE, n. 49, 1990. GIUSTI, Alejandro; CALVELO, Laura. "En busca de una medición de la reversibilidad", in CELTON, Dora Estela; DOMENACH, Hervé; GIUSTI, Alejandro (eds.). Migraciones y Procesos de Integración Regional. Córdoba: II Congreso Europeo de Latinoamericanistas-UNC-UBA, 1999.

LAGO, Luciana C. Estruturação urbana e mobilidade espacial: uma análise das desigualdades socioespaciais na Metrópole do Rio de Janeiro. São Paulo. Tese (Doutorado) - Faculdade de Arquitetura e Urbanismo (FAU), USP, 2000.

MARTINE, George. "Adaptação dos migrantes ou sobrevivência dos mais fortes?", in MOURA, H. (org.). Migrações internas. Fortaleza, BNB-Etene, v. 2, 1980, p. 949-974.

. "As migrações de origem rural no Brasil: uma perspectiva histórica", in Fundação SEADE. História e população: estudos sobre a América Latina. São Paulo: Fundação SEADE, 1990.

. "Os dados censitários sobre migrações internas: evolução e utilizações", in Encontro Nacional de Estudos Populacionais, 4, 1984, Águas de São Pedro. Anais... São Paulo: ABEP, v. 1, 1984.

MARTÍNEZ PIZARRO, Jorge. La medición e información sobre la medición internacional a partir de los censos: lecciones, desafíos y oportunidades. CELADE, 2008.

MARTINS, José de Souza. A sociedade vista do abismo: novos estudos sobre exclusão, pobreza e classes sociais. Petrópolis: Vozes, 2002.

MATOS, Ralfo Edmundo S. "A desconcentração populacional em Minas Gerais e as mudanças na Região-Core", in Encontro Nacional de Estudos Populacionais, 9., 1994, Caxambu. Anais... Belo Horizonte: ABEP, 1994.

NACIONES UNIDAS. Métodos de medición da la migración interna. Manual VI). Nueva York: Naciones Unidas, 1972.

PATARRA, Neide; CUNHA, João Marcos P. "Migração um tema complexo", in Revista São Paulo em Perspectiva, v. 1, n. 2, jul/set, 1987.

RIBEIRO, José T. L. Estimativa da migração de retorno e de alguns de seus efeitos demográficos indiretos no Nordeste Brasileiro. Belo Horizonte, 1997. Tese (Doutorado) - CEDEPLAR, Universidade Federal de Minas Gerais.

RIGOTTI, José Irineu R. "Dados censitários e técnicas de análise das migrações no Brasil: avanços e lacunas", in CUNHA, José Marcos (org.). Mobilidade espacial 
da população: desafios teóricos e metodológicos para o seu estudo. Campinas: NEPO/UNICAM, 2011.

; Técnicas de mensuração das migrações, a partir de dados censitários:

aplicação aos casos de Minas Gerais e São Paulo. Belo Horizonte, 1999. Tese (Doutorado) - CEDEPLAR, Universidade Federal de Minas Gerais.

; RODRIGUES, Roberto N. "Distribuição espacial da população na Região Metropolitana de Belo Horizonte", in Encontro Nacional de Estudos Populacionais, 9., 1994, Caxambu. Anais... Belo Horizonte: ABEP, 1994.

SALIM, Celso A. Estrutura agrária e dinâmica migratória na Região Centro-Oeste, 19701980: análise do êxodo rural e da mobilidade da força de trabalho no contexto de industrialização da agricultura e da fronteira urbanizada. Belo Horizonte, 1992. Tese (Doutorado em Demografia) - CEDEPLAR/FCACE, UFMG.

WUNSCH, Guillaume; TERMOTE, Marc G. Introduction to Demographic Analysis: principles and Methods. New York: Plenum Press, 1978.

ZELINSKY, Wilbur. "The hypothesis of the mobility transition", in Geographical Review, v. 6, n. 2, 1971.

\section{Abstract}

\section{Portraits of spatial mobility in Brazil: demographic census} as a source of data

Brazilian Censuses present a great wealth of information, being, in general, comparable over time. In this sense, they represent a great opportunity for people to learn different aspects of Brazilian population dynamics. Given the importance of migration in national demographic history, this article intends to rescue some theoretical and methodological features for the use of census data, in order to guide people who are interested in deepening their knowledge on the phenomenon.

Keywords: Migration; Internal Migration; Sources of Demographic Data; Demographic Census.

Recebido para publicação em 05/09/2012.

Aceito para publicação em 19/10/2012.

Received for publication in September, 05 ${ }^{\text {th }}, 2012$.

Accepted for publication in October, 19 2012. 